\title{
PERBANDINGAN TINGKAT KESEJAHTERAAN ANTARA PETANI SAWIT PLASMA \\ DAN NON PLASMA DI DESA SINUNUKAN IV KECAMATAN SINUNUKAN KABUPATEN MANDAILING NATAL PROVINSI SUMATERA UTARA
}

\author{
Lila Susiarti \\ Program Studi Geografi \\ Fakultas Ilmu Sosial Universitas Negeri Padang \\ Email : Lilasusiarti00@Gmail.com
}

\begin{abstract}
ABSTRAK
Petani kelapa sawit di Desa Sinunukan IV dibedakan dalam kategori petani plasma dan petani non plasma. Tujuan penelitian ini untuk melihat perbedaan tingkat kesejahteraan antara Petani Plasma dan Non Plasma.Metode penelitian dengan menggunakan deskriptif kuantitatif. Penarikan sampel secara Proportional sampling dengan jumlah 45 petani Plasma dan 67 petani non plasma. Variabel meliputi Tingkat pendapata, tingkat pendidikan, keadaan dan fasilitas tempat tinggal. Perolehan data menggunakan teknik wawancara, observasi dan studi kepustakaan. Hasil penelitian menunjukkan bahwa Kesejahteraan yang dimiliki anatara petani plasma dan non plasma terlihat petani non plasma lebih sejahtera dilihat dari tingkat pendapatan dari hasil perkebunan dan pekerjaan sampingan yang lebih besar diterima petani non plasma dibandingkan petani plasma, tingkat pendidikan orang tua dan anak lebih tinggi yang ditempuh keluarga petani non plasma daripada petani plasma, keadaan dan fasilitas tempat tinggal oleh petani non plasma lebih baik dan bersih.untuk kepemilikan transportasi antara petani plasma dan non plasma sama.
\end{abstract}

Kata Kunci : Perbandingan, Tingkat kesejahteraan, Petani Kelapa Sawit.

\begin{abstract}
Oil palm farmers in the village of Sinunukan IV are divided into categories of plasma farmers and non-plasma farmers. The purpose of this research is to see the difference of welfare level between Plasma and Non Plasma Farmer. Method of research using quantitative descriptive. Sampling by Proportional sampling with 45 Plasma farmers and 67 non-plasma farmers. Variables include Level of lecture, education level, circumstances and residential facilities. Obtaining data using interview techniques, observation and literature study. The results showed that the welfare owned by plasma and non-plasma farmers are seen more prosperous non-plasma farmers viewed from the income level of plantation products and the bigger side job received by non-plasma farmers than the plasma farmers, higher levels of parent and child education by nonplasma farmers 'families than plasma farmers, non-plasma farmers' better living conditions and facilities. For transport ownership between plasma and non-plasma farmers alike.
\end{abstract}

\section{Keywords: Comparison, Welfare Level, Farmers of Oil Palm.}

\footnotetext{
${ }^{1}$ Artikel ini ditulis dari skripsi penulis dengan judul Perbandingan Tingkat Kesejahteraan Antara Petani Sawit Plasma dan Non Plasma di Desa Sinunukan IV Kecamatan Sinunukan Kabupaten Mandailing Natal Provinsi Sumatera Utara September 2017
} 


\section{PENDAHULUAN}

Tanaman

perkebunan

merupakan salah satu komoditi ekspor di Indonesia, salah satunya adalah tanaman kelapa sawit. Indonesia merupakan negara penghasil kelapa sawit terbesar kedua setelah Malaysia. Kelapa sawit Indonesia sebagian besar berasal dari daerah Sumatera (Statistik perkebunan 2008-2010).

Penduduk Indonesia sebagian besar bertempat tinggal di daerah pedesaan serta mata pencarian adalah bertani. Menyadari hal ini, maka untuk meningkatkan taraf hidup mereka, pemerintah melalui pembangunan selalu menitik beratkan pada sektor pertanian.Hasilpertanian/perkebunan diharapkan dapat meningkatkan kesejahteraan dan kemakmuran rakyat dan kesejahteraan rakyat.

Hasil pertanian/perkebunan diharapkan dapat meningkatkan kesejahteraan dan kemakmuran rakyat, Hubungan antara pertumbuhan ekonomi dengan kesejahteraan masyarakat yaitu jika pertumbuhan ekonomi meningkat maka tingkat Kesejahteraan masyarakat juga akan meningkat.Masyarakat sejahtera merupakan masyarakat yang mampu menggunakan sumber pendapatannya untuk memenuhi kebutuhan seharihari.

Dalam rangka menunjang pembangunan pada sektor pertanian, terutama sub sektor perkebunan sebagai upaya peningkatan pendapatan para petani, pemerintah berupaya mendorong masuknya investasi asing dan lokal, Tentu kebijakan ini merupakan salah satu langkah strategis pemerintah dalam rangka pemberdayaan peningkatan kesejahteraan petani serta terbukanya.

Menurut sumber kajian iventarisasi potensi sumber daya alam wilayah Kabupaten Mandailing Natal merupakan salah satu kabupaten yang sangat pesat perkembangan pertanian kelapa sawit. Iklim dan topografi dengan daratan rendah dan sebagian merupakan daerah perbukitan yang bergelombang mendukung dan cocok untuk mengembangkan tanaman kelapa sawit.

Berdasarkan

lokasi

Kabupaten Mandailing Natal banyak penduduk pendatang yang tinggal di kabupaten ini yang termasuk daerah transmigran.Kegiatan mata pencarian para pendatang yang tinggal di Kabupaten Mandailing Natal sebagian besar sebagai petani kelapa sawit. Salah satu daerah penghasil kelapa sawit di Kabupaten Mandailing Natal adalah Kecamatan Sinunukan yang merupakan kawasan transmigrasi.

Di Desa Sinunukan IV Kecamatan Sinunukan petani sawit dibedakan dalam dua kategori yaitu petani plasma dan petani non plasma. Petani plasma yang merupakan pola pembinaan dan kerjasama antara perusahaan dengan masyarakat di sekitar lokasi perkebunan yang menjadikan masyarakat petani plasma mempunyai penghasilan tetap setiap bulan. Berbeda dengan petani 
non plasma yang membudidayakan perkebunan kelapa sawit secara pribadi tanpa kerjasama dengan pihak lain yang bebas melakukan perawatan dan pemeliharaan serta bebas memasarkan hasil kelapa sawitnya.

Perbedaan pola usaha tani tersebut tentu saja banyak terdapat ketidaksamaan antara petani sawit plasma dan petani sawit non plasma yakni dari segi pemeliharaan, pengelolaan,pemakaianpupuk, panen hingga tingkat kesejahteraannya yang dapat di lihat dari pendapatan masing-masing hasil panen buah sawit setiap bulannya. Oleh karena itu, perlu diketahui perbedaan sosial ekonomi antara kedua petani tersebut.

\section{METODE PENELITIAN}

\section{Jenis Penelitian}

Jenis penelitian yang dilakukan adalah penelitian deskriptif kuantitatif. Metode kuantitatif menurut Sugiyono (2009:8) dikatakan metode penelitian kuantitatif karena data penelitian yang diperoleh berupa angka-angka dan analisisnya menggunakan statistik. Sedangkan jenis penelitian ini adalah penelitian kuantitatif korelasional yaitu Penelitian yang dilakukan oleh peneliti untuk mengetahui tingkat hubungan antara dua variabel atau lebih, tanpa melakukan perubahan, tambahan atau manipulasi terhadap data yang memang sudah ada
(Arikunto, 2010:4). Jadi penelitian deskriptif kuantitatif adalah penelitian yang menggambarkan perbandingan sosial ekonomi masyarakat petani sawit plasma dan non plasma dengan menggunakan angka. Misalnya, tingkat pendapatan masyarakat dapat melalui tabel atau grafik.

\section{Lokasi dan Waktu Penelitian}

Lokasi penelitian berada di Desa Sinunukan IV. Sinunukan adalah sebuah kecamatan di Kabupaten Mandailing Natal, Sumatera Utara. Kecamatan ini termasuk kawasan pantai barat Sumatera Utara yang komoditi utama masyarakatnya adalah pertanian dan perkebunan kelapa sawit.Waktu penelitian pada Bulan Mei - Juni 2017. Peta Lokasi Penelitian dapat dilihat pada Gambar 1 berikut: 
Gambar 1. Peta Lokasi Penelitian

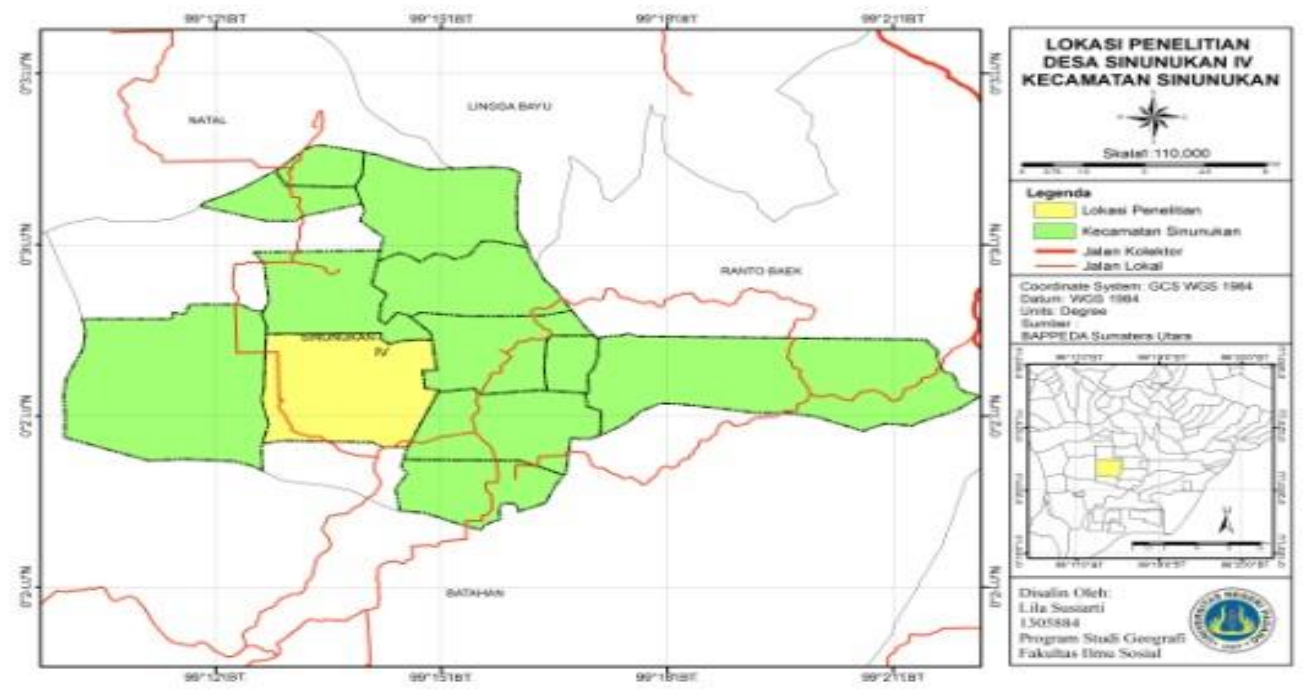

\section{Populasi dan Sampel Penelitian}

Dalam penelitian ini populasi seluruh petani kelapa sawit Plasma dan Non Plasma yang melakukan kegiatan perkebunan kelapa sawit di Desa Sinunukan Kecamatan Sinunukan. Total Populasi petani Kelapa sawit plasma dan non plasma adalah sebagai berikut:

Tabel 1.Populasi

\begin{tabular}{|c|c|c|c|}
\hline No & $\begin{array}{c}\text { Pola Usaha } \\
\text { Tani }\end{array}$ & Petani & Sampel \\
\hline 1 & Plasma & 82 & 45 \\
\hline 2 & Non Plasma & 208 & 67 \\
\hline & Jumlah & 290 & 112 \\
\hline
\end{tabular}

Sampel Penelitian diambil dengan cara proportional sampling. Yaitu menentukan anggota sampel dengan mengambil wakil-wakil dari tiap-tiap kelompokUntuk menentukan jumlah dari responden setiap Desa, maka digunakan

perhitungan menggunakan Rumus Slovin seperti berikut:

$$
\mathrm{n}=\frac{\mathrm{N}}{1+\mathrm{Ne}^{2}}
$$

\section{Variabel DefenisiOperasional}

a. Karakteristik perkebunan yaitu yang dibatasi untuk melihat bibit yang digunakan petani di Sinunukan serta jenis dan dosis 
pupuk yang dipakai untuk pemeliharaan perkebunan kelapa sawit agar terlihat hasil yang berkualitas.

b. Tingkat Pendapatanyaitu pendapatan yang di terima oleh petani sawit plasma dan non plasma yakni dari hasil panen perkebunan kelapa sawitnya dan pendapatan diluar dari perkebunan kelapa sawit yakni pendapatan pekerjaan sampingan yang dimiliki.

c. Tingkat pendidikan keluarga yaitu tingkat pendidikan yang dimiliki oleh keluarga petani plasma dan non plasma, yakni jenjang tertinggi pendidikan orang tua dan pendidikan anak.

d. Keadaan fasilitas tempat tinggal yang ditempati yakni petani sawit plasma dan non plasmamerupakan kepemilikan rumah yang dimiliki oleh petani.

e. Transportasi yaitu kepemilikan jenis transportasi oleh petani plasma dan non plasma dan jenis trsnportasi apa yang dijadikan akses menuju perkebunan kelapa sawitnya.

\section{Sumber Data}

\section{a. Data Primer}

Data primer yaitu data yang langsung dikumpulkan dari responden yakni data anggket dan observasi.

b. Data sekunder

Data sekunder yaitu data yang diperoleh dari catatan dan arsip yang ada pada instansi terkait seperti BPS. Dalam penelitian ini yang termasuk data sekunder ialah data penduduk yang didapat dari Kantor Kecamatan Sinunukan

\section{Tahap-Tahap Penelitian}

a. Studi kepustakaan

Studi kepustakaan ini dilakukan untuk menemukan literatur yang berkaitan dengan variabel penelitian dengan maksud melandasi variabelvariabel tersebut agar lebih reliebel dengan tujuan yang hendak dicapai.

b. Tahap pra lapangan

Tahap pra lapangan ini meliputi: a) penyusunan rencana penelitian, b) menentukan lapangan penelitian, c) mengurus perizinan, d) menjajaki dan meneliti keadaan lapangan, e) memilih dan memanfaatkan informasi, f) menyiapkan perlengkapan untuk melakukan penelitian dan g) persoalan etika lapangan.

c. Tahap pekerjaan

Tahap ini meliputi: a) memahami latar penelitian, b) turun kelapangan dan c) berperan dalam pengumpulan data.

d. Tahap analisis

Tahap ini meliputi: a) konsep dasar analisis data, b) memberikan penafsiran 
terhadap data dan c) melakukan pencatatan analisa data.

\section{Teknik Analisa Data}

Sesuai dengan tujuan penelitian maka data yang diperoleh diolah dengan menggunakan analisa deskriptif dengan rumus presentasi untuk melihat kecende rungan masingmasing variabel, menggunakan rumus sebagai berikut :

$$
\mathrm{P}=\frac{f}{N} x 100 \%
$$

\section{HASIL DAN PEMBAHASAN}

Untuk mengetahui hasil penelitian mengenai perbandingan Tingkat Kesejahteraan antara petani sawit plasma dan non plasma di Desa Sinunukan IV Kecamatan Sinunukan penulis menyebarkan angket dan ditabulasidimana Kepala Keluarga yang dijadikan responden. pengolahan data yang dilakukan untuk masing-masing variabel penelitian ini dilakukan deskripsi dengan tujuan menggambarkan proporsi jawaban responden terhadap variabel penelitian.

\section{Tingkat pendapatan}

tingkat pendapatan yang diperoleh dari hasil perkebunan petani plasma dari 45 orangresponden memberikan tanggapan 45 orang responden
$(100,00 \%)$ menyatakan bahwa penghasilan setiap bulannya dari pasca panen berkisar Rp.5.000.000 dan 0 responden $(00,00 \%)$ menyatakan bahwa penghasilan setiap bulannya pasca panen Rp.6.800.000.

Sementara petani sawit non plasma dari 67 orang responden meberikan tanggapan sebagai berikut: 67 responden $(100,00 \%)$ menyatakan bahwa penghasilan setiap bulannya pasca panen berkisar Rp.7.200.000 dan 0 responden $(00,00 \%)$ menyatakan bahwa penghasilan setiap bulannya pasca panen Rp.5000.000.

penghasilan yang diperoleh dari pekerjaan sampingan yang dimiliki petani plasma dari 45 orang responden memberikan tanggapan sebagai berikut: 11 orang responden (24,4\%) menyatakan penghasilan yang diterima dari pekerjaan sampingan Rp.2000.000, 12 responden $(26,6 \%)$ menyatakan penghasilan yang diperoleh dari pekerjaan sampingan yaitu $\mathrm{Rp}$. 1000.00017 responden $(37,78 \%)$ menyatakan penghasilan yang diterima dari pekerjaan sampingannya yaitu Rp. 3.000.000 dan 5 orang responden lainnya $(11,11 \%)$ menyatakan penghasilan yang diperoleh dari pekerjaan sampingan yaitu Rp. 3.500.000. Sedangkan pada petani non plasma dari 67 orang responden mengatakan bahwa 20 orang responden $(29,8 \%)$ menyatakan penghasilan yang 
diterima dari pekerjaan sampingannya yaitu Rp. 2000.000, 15 orang responden $(22,38 \%)$ menyatakan penghasilan yang diterima dari pekerjaan sampingannya yaitu Rp. 1000.000, 17 orang responden $(25,37 \%)$ menyatakan penghasilan yang diterima dari pekerjaan sampingannya yaitu Rp. 3000.000 dan 15 orang responden lainnya (22,38\%) menyatakan Penghasilan yang diterima dari pekerjaan sampingannya adalah Rp. 3.500.000.

\section{Tingkat Pendidikan}

Tabel 2 Pendidikan Responden Petani Sawit

\begin{tabular}{|l|l|r|r|}
\hline No & $\begin{array}{c}\text { Tingkat } \\
\text { Pendidikan }\end{array}$ & Plasma & $\begin{array}{c}\text { Non } \\
\text { Plasma }\end{array}$ \\
\hline 1 & Tidak Sekolah & 1 & 4 \\
\hline 2 & Tamat SD & 20 & 34 \\
\hline 3 & Tamat SMP & 18 & 14 \\
\hline 4 & Tamat SMA & 5 & 12 \\
\hline 6 & $\begin{array}{l}\text { Perguruan } \\
\text { Tinggi }\end{array}$ & 1 & 3 \\
\hline & Jumlah & 45 & 67 \\
\hline
\end{tabular}

\section{Tabel 3 Pendidikan Anak Responden}

\begin{tabular}{|l|l|r|r|}
\hline No & $\begin{array}{l}\text { Tingkat } \\
\text { Pendidikan }\end{array}$ & Plasma & $\begin{array}{c}\text { Non } \\
\text { Plasma }\end{array}$ \\
\hline 1 & $\begin{array}{l}\text { Belum } \\
\text { Sekolah }\end{array}$ & 6 & 32 \\
\hline 2 & $\begin{array}{l}\text { Tidak } \\
\text { Sekolah }\end{array}$ & - & 4 \\
\hline 3 & TK/Paud & - & 11 \\
\hline
\end{tabular}

\begin{tabular}{|l|l|r|r|}
\hline 4 & SD & 13 & 51 \\
\hline 5 & Tamat SD & 3 & - \\
\hline 6 & SMP & 8 & 8 \\
\hline 7 & Tamat SMP & 31 & 22 \\
\hline 8 & SMA & 21 & 24 \\
\hline 9 & Tamat SMA & 63 & 19 \\
\hline 10 & $\begin{array}{l}\text { Perguruan } \\
\text { Tinggi }\end{array}$ & 21 & 4 \\
\hline & Jumlah & 166 & 175 \\
\hline
\end{tabular}

\section{Keadaan dan fasilitas tempat tinggal}

Status tempat tinggal yang ditempati dari 45 orang responden petani plasma mengatakan 41 orang tempat tinggal milik sendiri, 10 orang tempat tinggal milik orang tua, dan 1 orang mengatakan tempat tinggal menyewa. Dan pada petani non plasma dari 67 orang responden mengatakan 54 orang mengatakan tempat tinggal milik sendiri, 3 orang mengatakan tempat tinggal milik orang tua dan tidak ada responden yang mengatakan tempat tinggal menyewa.

Fasilitas kamar mandi yang dimiliki petani plasma dan non plasma hampir keseluruhan responden mengatakan memiliki fasilitas kamar mandi dan WC.

Keseluruhan orang responden mengatakan sumber penerangan yang dimiliki petani plasma dan non plasma listrik dari PLN yang melalui sambungan sendiri.

Tabel 4.Bahan Bakar yang digunakan Responden

\begin{tabular}{|l|c|c|c|c|c|}
\hline \multirow{2}{*}{ No } & \multirow{2}{*}{$\begin{array}{c}\text { Jenis Bahan } \\
\text { bakar yang } \\
\text { digunakan }\end{array}$} & \multicolumn{2}{|c|}{$\begin{array}{c}\text { Petani } \\
\text { plasma }\end{array}$} & \multicolumn{2}{c|}{$\begin{array}{c}\text { Petani non } \\
\text { plasma }\end{array}$} \\
\cline { 3 - 6 } & f & $\%$ & $\mathrm{f}$ & $\%$ \\
\hline 1 & Tungku & 10 & 22,2 & 7 & 10,4 \\
\hline
\end{tabular}




\begin{tabular}{|l|l|c|c|c|c|}
\hline 2 & $\begin{array}{l}\text { Kompor } \\
\text { Sumbu }\end{array}$ & 15 & 33,3 & 10 & 14,9 \\
\hline 3 & $\begin{array}{l}\text { Kompor } \\
\text { Gas }\end{array}$ & 20 & 44,4 & 50 & 74,6 \\
\hline \multicolumn{2}{|c|}{ Jumlah } & 45 & $\begin{array}{c}100 \\
\%\end{array}$ & 67 & $\begin{array}{c}100 \\
\%\end{array}$ \\
\hline
\end{tabular}

\section{Transportasi}

Dari hasil dilapangan terlihat seluruh responden mengatakan transportasi yang dimiliki berjenis motor dan mobil, yang digunakan sebagai akses menuju perkebunan kelapa sawitnya.

\section{PEMBAHASAN}

Penelitian ini bertujuan membandingkan tingkat kesejahteraan antara petani plasma dan non plasma didesa Sinunukan IV yang para masyarakatnya telah melakukan usaha taninya sudah 20 tahun lebih dengan pembukaan lahan yang di mulai penanaman pada tahun 1995 berjalan hingga sampai sekarang ini. Karena budidaya kelapa sawit merupakan salah satu usaha perkebunan yang memberi keuntungan lebih, tentu hal ini akan membuat para masyarakat bertahan membudidayakan perkebunan kelapa sawit.

Kesejahteraan pada penilitian ini salah satunya diukur dari pendapatan yang diterima setiap bulannya dari hasil panen, untuk menentukan hasil panen Berikut ini dapat dijelaskan analisis usaha budidaya sawit yang telah dilakukan oleh para petani sawit di desa Sinunukan IV.

\section{Tingkat Pendidikan}

Tingkat pendapatannya lebih tinggi. Pendapatan diterima dari hasil perkebunan dan pendapatan dari pekerjaan sampingan yang dimiliki lebih tinggi petani non plasma menerima dari pada petani plasma.

\section{Tingkat Pendidikan}

Tingkat pendidikannya lebih tinggi. Karena pendidikan merupakan salah satu faktor penentu peningkatan kesejahteraan masyarakat, terlihat jenjang pendidikan terakhir yang ditempuh oleh petani non plasma lebih tinggi karena banyak yang tamat SMA dan Perguruan tinggi daripada petani plasma yang hanya tamat SD dan tamat SMP. Pada pendidikan anak terlihat anak dari responden petani non hampir keseluruhan anaknya bersekolah dengan pendidikan tertinggi yang ditempuh SMA dan perguruan tinggi, sedangkan pada anak responden dari petani plasma masih terdapat anaknya yang tidak sekolah dan ada yang hanya tamat SD. Disini terlihat pendidikan anak dari petani non plasma lebih tinggi dan baik pendidikannya daripada pendidikan anak dari responden petani plasma.

\section{Keadaan dan Fasilitas Tempat} tinggal Responden 
Keadaan dan fasilitas tempat tinggal yang baik dan bersih. Dimana responden dari petani non plasma satatus kepemilikan rumah meraka rumah sendiri dibangun dengan biaya sendiri sedangkan petani plasma rumah yang ditempati adalah milik orang tua dan menyewa/ ngontrak. pada sumber air bersih pada petani plasma seluruh responden memakai air untuk CMCK berasal dari sumur dan sumur bor miliki sendiri sedangkan petani non plasma masih ada responden yang memakai air bersih dari sumur umum. Dan bahan bakar yang digunakan petani non plasma lebih merata memakai kompor Gas dari pada petani plasma yang masih banyak menggunakan kompor sumbu dan tungku.

\section{Transportasi}

Trasnportasi yang dimiliki oleh responden petani plasma dan non plasma tidak ada perbedaan. Transportasi yang dimiliki adalah berjenis motor dan mobil yang digunakan untuk akses menuju perkebunan

Petani plasma dan non plasma sama-sama menggunakan trasnportasi berjenis motor milik pribadi, namun untuk pekerja ataupun karyawan pada petani plasma yang tidak memiliki tranportasi akan dijemput kerumah masing-masing.

\section{PENUTUP}

\section{Kesimpulan}

Pendapatan dari hasil perkebunan dan pekerjaan sampingan terlihat petani non plasma lebih besar menerima setiap bulannya dibandingkan petani plasma.

Tingkat pendidikan yang ditempuh petani non plasma lebih tinggi dari pada petani plasma, dan pada pendidikan anak keseluruhan anak petani non plasma bersekolah dengan jenjang pendidikan tertinggi SMA dan perguruan tinggi, berbeda dengan anak dari responden petani plasma yang anaknya masih ada yang tidak tamat sekolah bahkan sekolah hanya sampai SD saja. Kesejahteraan yang dilihat dari tingkat pendidikan tentu keluarga petani non plasma yang terlihat sejahtera.

Keadaan dan fasilitas tempat tinggal oleh petani non plasma lebih baik dan bersih dibandingkan petani plasma. Dimana petani non plasma hampir keseluruhan memiliki rumah sendiri dengan jenis semi permanen dengan sumber air bersih yang berasal dari sumur dan sumur bor, sumber penerangan yang bersumber dari listrik PLN melalui sambungan sendiri serta bahan bakar yang 
digunakan merata menggunakan kompor Gas semua.

Untuk transportasi tidak terdapat perbedaan antara petani plasma dan petani non plasma karena keseluruhan responden memiliki transportasi berjenis motor yang digunakan sebagai akses menuju perkebunan.

\section{Saran}

Para petani kelapa sawit plasma dan non plasma seharusnya lebih baik dalam pemeliharaan tanaman kelapa sawit dan sesuai dengan standar pemeliharaan.

Dari hasil penelitian yang saya lakukan sebaiknya Petani plasma lebih mempertimbangkan lagi apakah tetap ingin bekerjasama dengan PT atau tidak.

Para petani kelapa sawit plasma dan non plasma lebih mempehatikan lagi pada perawatan perkebunan kelapa sawitnya untuk mendapatkan hasil panen yang lebih baik lagi.

\section{DAFTAR PUSTAKA}

Arikunto, Suharsimi. 2006. Prosedur Penelitian.Jakarta : Rineka Cipta.

Badan Pusat Statistik. 2008. Statistik Kelapa Sawit Indonesia. Jakarta: CV. Sukorejo Bersinar.

Sugiyono. (2009). Metode Penelitian Bisnis (Pendekatan Kuantitatif, Kualitatif, dan $R \& D)$. Bandung: Alfabeta. 